\title{
Energy, Mass, Model-Based Displays, and Memory Recall
}

\author{
LEO BELTRACCHI, SENIOR MEMBER, IEEE
}

\begin{abstract}
The operation of a pressurized water reactor in the context of the conservation laws for energy and mass is discussed. These conservation laws are the basis of the Rankine heat engine cycle. Computer graphic implementation of the heat engine cycle, in terms of temperature-entropy coordinates for water, serves as a model-based display of the plant process. A human user of this display, trained in first principles of the process, may exercise a monitoring strategy based on the conservation laws.
\end{abstract}

\section{INTRODUCTION}

$\mathrm{T}$ HE CONTROL ROOM of a nuclear power plant consists of control boards and human operators. The control boards for plants within the United States employ analog hardwired technology. However, this is changing as digital technology replaces worn-out analog hard-wired components. A control board contains operator interfaces for open- and closed-loop control systems. These interfaces consist of work stations containing switches and setpoints. The control boards also contain meters, gauges, and indicator lights. Instruments serve to display process variables and system variables for the operator's use. Some of these process variables monitor the nuclear fission process, while others monitor the heat engine cycle. However, with analog hard-wired technology one sensor requires one instrument and a major process control function requires one control panel. This structure results in a large control board, which requires more than one operator to monitor and operate.

Control room operators run the plant. To run the plant operators interface with the control board. The operator's interaction with the control board consists of two types of action: tasks of execution and tasks of evaluation. In tasks of execution the operator initiates a control action such as starting a pump or closing a valve. These are physical tasks. In doing so the operator interacts with devices such as switches on the control board. In tasks of evaluation the operator assesses data from instruments and displays. Examples of these tasks are monitoring operations, diagnosing abnormal operations, and evaluating the plants conformance to the technical specifications of operation. These are mental tasks requiring cognitive behavior. Startup, shutdown, and emergency operation procedures serve to guide operators in running the plant. These procedures consist of tasks of execution and tasks of evalua-

Manuscript received October 10, 1988; revised January 17, 1989. The author is with the U.S. Nuclear Regulatory Commission, Washington, DC 20555.

IEEE Log Number 8928097. tion. In executing these procedures, the operators perform rule-based behavior.

Rule-based procedures are extremely useful in responding to the large majority of situations that confront operators. However, operating history with nuclear power plants indicates that events do occur wherein operators have no procedures to guide their actions. In these cases control room operators must resort to knowledge-based behavior to resolve a problem. This requires operators to employ fundamental engineering principles to diagnose a problem, plan a corrective action, and then execute the action. In a pressurized water reactor (PWR) this means that an operator should have a fundamental understanding of the properties of water, the nuclear fission process, and the heat engine cycle. The human operator must also know the operation of plant systems, the unique properties of plant systems, and how systems interact with the process. These important details may be difficult to recall from human memory while under stress. Failure to recall these details may result in human error and challenges to plant safety.

The degree of synergism between a human operator and the control board is a function of the operator's training and the design of the interface. With analog hard-wired technology the syntax of the interface language in tasks of evaluation consists of individual process variables and system variables. The human operator is responsible for integrating these variables into process functions and then the process functions into the heat engine cycle. Finally, the operator evaluates the state of the process versus the goals of operation.

The introduction of digital computers and computer-driven cathode-ray tubes provides an opportunity to simplify the interface. By using graphics as the syntax of the interface language, an icon of the process serves to integrate process functions into a heat engine cycle, resulting in a model-based display. The Rankine cycle, a heat engine cycle, serves as the basis of the model-based display discussed in this technical paper. Examples of model-based displays are in [2]-[4]. Reference [3] also presents a concept for the control of the heat engine cycle from the digital-based interface. In this context the heat engine cycle becomes the object in a direct manipulation interface. However, with analog hard-wired technology one sensor requires one instrument and a major process control function requires one control panel.

Other topics for discussion in this report consist of the operator's mental model of the plant, knowledge-based behavior, and the degree of synergism between the operator and the model-based display. A large majority of this discussion rests 
upon the products from the works of $\mathrm{J}$. Rasmussen and $\mathrm{K}$. Vicente [5], [6].

The object of this work is to narrow the gap between theory and operation by means of a model-based display based upon the Rankine cycle. The specific model-based display discussed could serve as an operator interface within the control room of a pressurized water reactor. The model-based display consists of a process icon and a system icon. The theoretical basis of the process icon rests with the fundamental laws of thermodynamics. These fundamental laws address energy and mass. The system icon synthesizes the operation of plant water systems that interact with the process. Appendix I provides a list of thermodynamic terms and a source of their definition. Appendix II identifies some of the basic terms useful in the discussion of human-machine interfaces. The results of an analysis on a pressurized water reactor utilizing the fundamental laws of thermodynamics identify the main variables for evaluating the process. A computer's synthesis of these process variables results in an articulation of the process in the form of a real-time model (on a cathode-ray tube) of the cycle.

\section{The Rankine Cycle}

The Rankine cycle is a heat engine power cycle. The basic Rankine cycle consists of four process functions. These are

1) heat addition to a working fluid, which results in a phase change for the fluid from a liquid to a vapor,

2) an isentropic reversible expansion of the fluid, which does work upon a turbine,

3) a reversible heat-rejection process of condensation, which results in a phase change from a vapor to a liquid for the fluid, and

4) an isentropic compression of the liquid by means of pump work.

Fig. 1 illustrates the basic Rankine cycle in terms of temperature-entropy coordinates for the working fluid water. Heat addition to the subcooled water (point $b$ ) raises the water's temperature to saturation temperature (point $c$ ). Continued heat addition to the saturated water results in boiling, which converts saturated water to saturated steam (point $c$ to point $d$ ). An isentropic reversible expansion of the steam performs work upon a turbine (point $d$ to point $e$ ). Heat rejection to the environment in the condenser condenses steam to saturated water (point $e$ to point $a$ ). The environment consists of water at a colder temperature than the steam's temperature in the condenser; thus it serves as a heat sink. Finally, isentropic compression of the liquid water by pump work raises the pressure of the water from condenser pressure to steam generator pressure (point $a$ to point $b$ ), which completes the cycle. Reference [1] contains additional detail on the Rankine cycle.

In real-world performance the basic Rankine cycle is unachievable. Frictional losses such as pressure losses resulting from the flow of water in a pipe are the main reasons why ideal performance is unachievable. However, real-world performance of a process function relates to ideal performance by an efficiency factor. For example, because of frictional losses, pump work upon the fluid water during the compres-

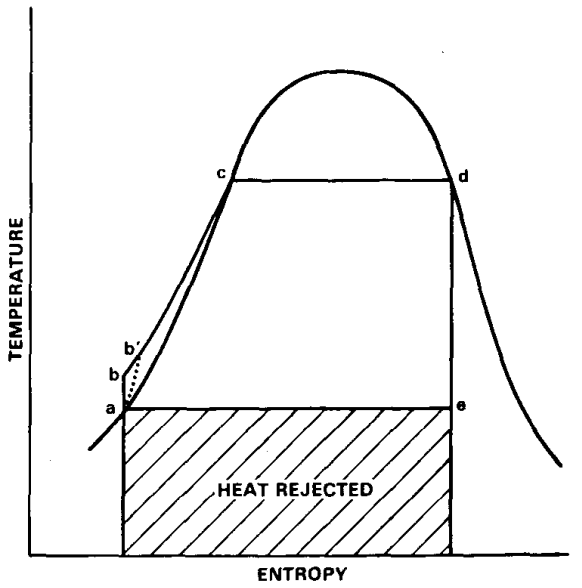

Fig. 1. Rankine cycle (temperature rise $a b$ greatly exaggerated) with water as working fluid.

sion process is greater than the ideal work needed to raise the pressure of the water. The frictional losses manifest themselves as an increase in water temperature when compared to the ideal process function. In Fig. 1 the actual pump work upon the fluid water is the process path $a b^{\prime}$. Also note this results in an increase in entropy when compared to the ideal compression process function $a b$. The ratio of ideal pump work to actual pump work establishes the efficiency of the compression process. Specific details on the real-world performance for the other process functions within the heat engine are in Obert [1].

The process within the secondary coolant loop of a pressurized water reactor relates directly to the Rankine cycle. The process experienced by the coolant water within a cycle for a boiling water reactor (BWR) also directly relates to the Rankine cycle. The measured properties of water such as temperature and pressure within the process cycle serve to formulate the Rankine cycle.

The thermodynamic law of the conservation of energy is a basis of the Rankine cycle. In this law the total heat added to the coolant minus the total heat lost from the coolant is the net work performed by the coolant. The total heat added to the coolant is the heat to raise feedwater temperature to saturation plus the heat to boil the saturated water to saturated steam. The heat lost by the coolant is the heat rejected through the condenser in condensing the vapor to a liquid and the heat losses from the coolant through the pipes. The net work performed by the cycle is the turbine work minus the pump work. Thus the Rankine cycle shows the distribution of energy within the cycle. This evaluation of energy distribution within the cycle is valid in steady-state as well as transient-state operation. The thermodynamic law on the conservation of energy also applies to the primary coolant system of a pressurized water reactor. The next section addresses this very point.

\section{A Model-Based Display}

A computer-generated process icon models the heat engine cycle. In a light-water-cooled nuclear power plant, this means the heat engine cycle from the heat source, the reactor, to the heat sink, the environment. The process icon is for water, the 
coolant, and it is in temperature-entropy space. The Rankine cycle serves as the basis of the process icon. The process icon also encodes water levels within the coolant systems. Examples of process icons for a PWR and BWR are in [2]-[4]. Most important of all, [7] describes an operational model-based display that is successfully monitoring the total heat engine cycle at Experimental Breeder Reactor II.

For a PWR at design power the process icon presents the state of water within each of the coolant loops. The flow path of the coolant in each loop is a closed cycle. Measured temperature and pressure data at various points in the coolant loop and the properties of water serve to identify these points within temperature-entropy space. Having the computer connect these points infers a coolant cycle within the plant and forms an icon for the operator to monitor. To eliminate this inference, one would need the technology to trace continuously and measure the thermodynamic properties of an element of coolant mass as it travels around the coolant cycle. Also, having the computer connect these points "chunks" all related data into a logical structure of temperatures for the cycle. Additional details on a process icon for PWR's are in [2].

The state of water in a pressurized water reactor is important data to evaluate in assessing the safety status of the reactor. The bell-shaped curve in the center of Fig. 1 describes the saturated state of liquid water and steam vapor. The portion of the curve to the left of the apex is the saturated water line. The portion of the curve to the right of the apex is the saturated steam line. The apex of the curve is known as the critical point, where saturated liquid and saturated steam are indistinguishable from one another. At the critical point the pressure is 3208 psia and the temperature is $705.5^{\circ} \mathrm{F}$. The saturation curve serves as the basis for a rapid assessment of the state of water within a plant and thus the safety status of the reactor.

The states of water as a function of temperature and entropy must be known to a human operator to evaluate the operational status of the reactor. To the left of the saturated water line (Fig. 1), the water is in a liquid state and subcooled. To the right of the saturated steam line, the water is in a vapor state and superheated. Between the saturated water line and the saturated steam line, saturated water and saturated steam coexist with one another. This basic knowledge of the properties of water must be known by a user to evaluate the safety status of water-cooled reactors. Subcooled liquid-phase water in the reactor core at steady-state conditions indicates that the core is adequately cooled. However, superheated steam in the core indicates inadequate cooling. These simple facts allow an operator to use pattern recognition in evaluating the process status and safety from the model-based display. Thus detailed thermodynamic knowledge of water is not necessary. Also, this display minimizes the need for steam tables as the pertinent data from the tables serve as the display's background.

\section{A. The Ideal Process Icon}

The process icon contains data that allow a user to evaluate the distribution of energy and mass within the heat engine cycle. To prove this statement we must analyze the process. We begin our discussion with an ideal process. To simplify this discussion we assume a pressurized water reactor at design power. The integrity of the coolant piping system, flow control valves, pressure relief valves, and coolant pumps is an assumption for this discussion. Furthermore, we assume that

1) the coolant systems need no make-up water and no leakages are occurring, which means that the mass of the coolant in the primary coolant loop and in the secondary coolant loop are each constant with time,

2) the coolant pipes are perfect insulators with no heat loss to the environment,

3) no heat is being added to the pressurizers in the primary coolant system, and

4) the coolant pumps in each coolant system are ideal pumps.

The internal volume identified by the physical systems that contain the primary coolant is a control volume. For this discussion we call it control volume 1. Fig. 2 illustrates a schematic of a PWR and the identity of control volume 1 . The outer surface of control volume 1 is also the reactor coolant pressure boundary. Another control volume is the internal volume identified by the physical systems that contain the secondary coolant. For this discussion we call this control volume 2, also shown in Fig. 2. The process within control volume 2 relates directly to the Rankine cycle. The process within control volume 1 is not a Rankine cycle, but it is a cycle. The primary coolant absorbs heat as it flows through the core and transports this energy to the steam generator within control volume 1 . The heat in the primary coolant serves as the heat source (via the steam generator) for the Rankine cycle in control volume 2 . Finally, we limit the scope of this discussion to control volume 1 of the heat engine cycle, and we will not discuss the fission process and radiation.

The concept of a control volume is a useful tool in the analysis. The control volume serves as a mechanism in accounting for energy and mass. Within the thermodynamic processes we use the control volume to express conservation laws for energy and mass. Simply stated, these laws are as follows.

Mass: Mass stored in a control volume is equal to the initial mass within a control volume and the integral of mass entering the control volume less the integral of mass leaving the control volume.

Energy: Energy stored in a control volume is equal to the initial energy within a control volume and the integral of energy entering the control volume less the integral of energy leaving the control volume.

Fig. 3 presents an overview of mass and energy within an ideal pressurized water reactor. The heat generated in the nuclear fission process goes to the primary coolant in the reactor core. The primary coolant transports heat from the core to the steam generators, wherein it loses heat to the secondary coolant. The primary coolant is then recirculated to the core by the pumps, and the cycle is then repeated. The primary coolant pumps perform work upon the coolant. The 


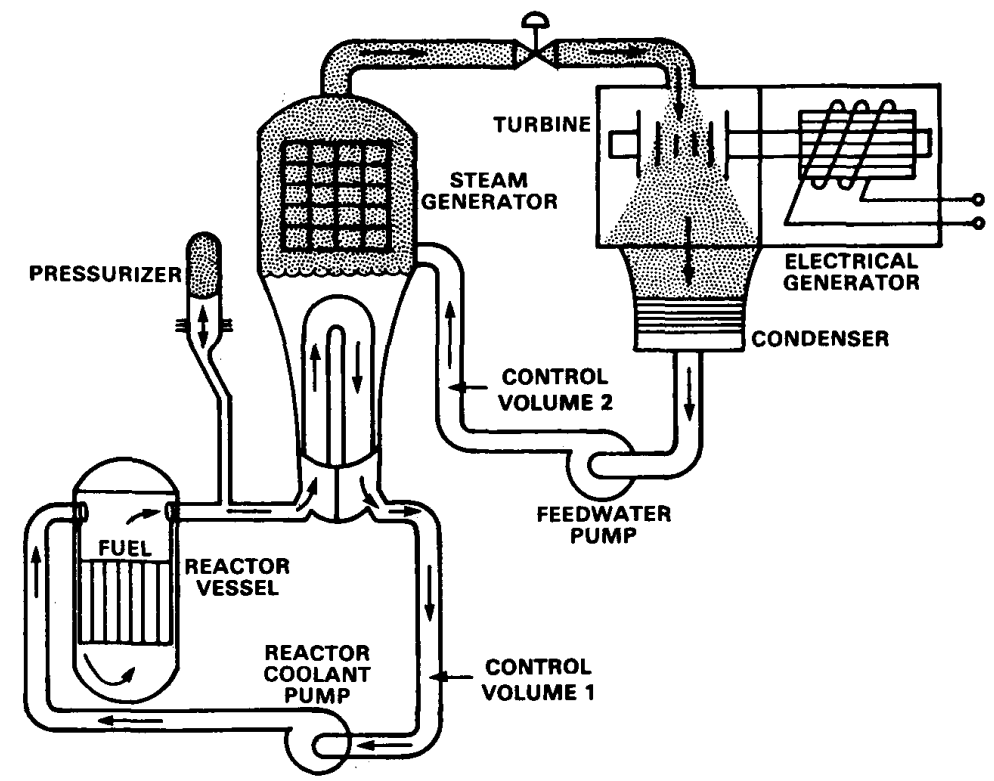

Fig. 2. Simplified schematic of pressurized water reactor plant.

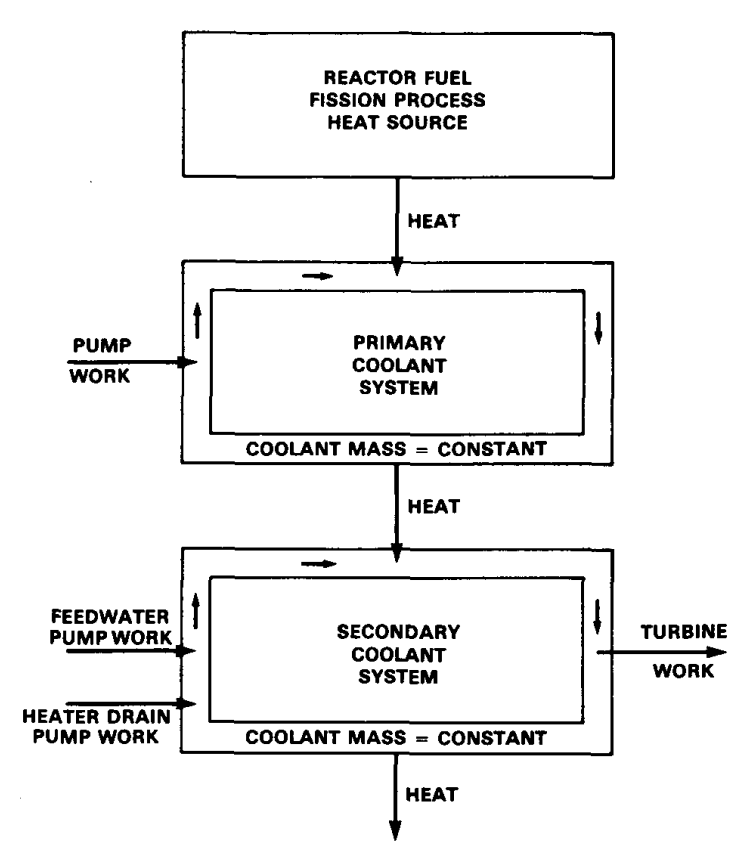

Fig. 3. Mass and energy overview of pressurized water reactor.

primary coolant system is control volume 1. From the conservation of energy and steady-state operation, the heat added to the coolant in the core plus pump work upon the coolant equals the heat rejected in the steam generator. The mass of the coolant in this control volume 1 is a constant since it is an ideal system. These facts illustrate the conservation law of energy and mass for control volume 1.

The secondary coolant absorbs heat from the primary coolant in the steam generator. Part of this heat performs turbine work and a large part of the remaining heat goes to the environment (a heat sink) from the condenser. The secondary coolant pumps perform work upon the coolant to recirculate the coolant from the condenser to the steam generators. Extraction steam from the turbine serves as a heat source to the feedwater heaters. The extraction steam and feedwater heating are not shown in Fig. 3. During the feedwater heating process the extraction steam condenses to liquid-phase water. A heater drain pump serves to recirculate the condensate from the feedwater heaters as feedwater. The heater drain pump performs work upon the feedwater heater condensate. The schematic in Fig. 3 accounts for this work.

From the conservation of energy and steady-state operation, turbine work by the coolant minus pump work upon the coolant, including heater drain pump work, is the heat added to the coolant minus the heat lost by the coolant. The secondary coolant system is control volume 2 . The mass of the coolant in this control volume is a constant since it is an ideal system. These facts illustrate the conservation law of energy and mass for control volume 2 . The discussion that follows provides further details on these laws.

The heat generated from nuclear fission enters control volume 1 in the reactor core. The fuel pins within the reactor core are not part of control volume 1 . The primary coolant receives this heat, resulting in a temperature rise of the coolant as it flows through the core. Upon leaving the reactor core, the primary coolant flows to heat exchangers (steam generators) in another region of control volume 1 . In the steam generators the hot primary coolant loses heat to a secondary coolant, which is also water. Heat leaves control volume 1 in these steam generators.

The primary pumps serve to circulate the coolant within the control volume. The work that the primary coolant pumps perform on the coolant compresses the coolant and raises its pressure. Thermodynamically, this work is an isentropic process. The pressure rise of the coolant as it flows through the pump is a measure of pump work upon the coolant. At 
design power the pump work performed upon the primary coolant is very small in comparison to the heat received by the coolant in the reactor core. When the coolant absorbs all of the heat generated by the reactor and the work done upon it by the pumps, and then loses the equivalent amount of heat in the steam generators, then a steady-state condition exists in the process. In a steady-state condition the process variables are constant with time. Steady-state operation reflects the conservation of energy for the coolant: heat added to the control volume plus work added to the control volume equals the heat lost from the control volume. In steady-state operation there is no change in the energy stored within the control volume.

The temperature rise of the primary coolant in the reactor core, in conjunction with the coolant flow, is a measure of the heat energy received in the reactor core. Conversely, the temperature drop of the primary coolant in a steam generator, in conjunction with the primary coolant flow through the steam generator, is a measure of the heat energy lost from control volume 1 . If the sum of the energy lost from all steam generators equals the energy received from the reactor core plus pump work on the coolant, then a steady-state condition exists. If the sum of the energy lost by the coolant from all stream generators is less than the heat received in the reactor core plus pump work, then the primary coolant heats up and coolant temperatures rise. Conversely, coolant temperatures fall if reactor heat plus pump work is less than heat lost from control volume 1 . These coolant states reflect the conservation of energy within control volume 1 .

The primary variables for tracking heat flow within the coolant loops are temperatures of the coolant and flow rate of the coolant. More specifically, the temperature drop or the temperature rise of a single-phase coolant as it passes through a heat exchanger is an indicator of heat flow within the exchanger. The differential temperature between inlet coolant temperature and exit coolant temperature serves as a measure of heat rate to a human operator. This is easily done when the ratio of heat rate to coolant flow rate is large, which means the temperature difference is significant. One example is the primary coolant temperature drop in the steam generator during design power operation. However, this is not effective when the ratio of heat rate to coolant flow rate is small. For example, during afterheat removal (also known as decay heat removal) operation, the temperature drop of the primary coolant in the steam generator may be less than the accuracy of the measuring thermocouples. The primary coolant temperature drop between the steam generator inlet and exit is a measure of the heat energy leaving control volume 1 . The point is that temperatures and coolant flow must be available as a function of time to monitor the distribution of energy within control volume 1 .

The mass of the coolant in control volume 1 is a constant with time for the stated assumptions. The mass of the coolant in the primary coolant system consists of the mass of liquidphase water and the mass of steam in the pressurizer. Because of differences in density, the mass of the steam is small with respect to the mass of the water. The volume of the steam is the volume of the pressurizer minus the volume of the liquidphase water in the pressurizer. The water level in the pressurizer determines water volume. The mass of the steam is then the product of the density of the steam and the volume of the steam. The mass of the steam within the pressurizer is important since it sets pressure in the primary coolant loop.

The density of the coolant water in control volume 1 varies with temperature and pressure. During transient operation of the reactor, wherein an imbalance exists between the total energy received and energy lost by the coolant water in control volume 1 , the average temperature of the coolant varies with time. In the event where the average temperature of the water rises and the water remains in a liquid phase, the water expands as it becomes less dense. The increased volume of water results in a higher water level in the pressurizer. Conversely, the water level in the pressurizer falls if the average temperature of the water falls. These actions of pressurizer water level reflect the fact that water density varies with temperature and the conservation of mass for control volume 1 . The point from this discussion is that the pressurizer water level, the average temperature of the water, and the subcooling of the water are important process variables to monitor the mass of the coolant water in control volume 1 .

The problem of monitoring the mass of the coolant becomes much more complex when saturated water and vapor also exist in the coolant loops as well as in the pressurizer. This problem is discussed later in this report.

The preceding discussion identified important process variables to monitor the distribution of energy and mass within control volume 1 for the stated assumptions. The distribution of energy in control volume 1 reflects the energy that crosses the surfaces of control volume 1 such as the heat transfer in a heat exchanger. Table I identifies these variables for the ideal operation of the plant. An analysis of control volume 2 would identify similar process variables to monitor.

The digital computer and high-resolution cathode-ray tubes are powerful interface design tools. These tools operate upon the process variables identified for control volumes 1 and 2 . The computer's synthesis of these process variables in terms of temperature-entropy space for water (Fig. 1) results in an iconic articulation of the process. The articulation of the process is in the form of a real-time model of the process based upon the Rankine cycle. Fig. 4 contains a process icon for a pressurized water reactor at design power. Details on how to generate and code the process icon in terms of temperatureentropy space are in [3]. Also, [9] discusses the cognitive color coding of the display format.

The process icon serves as a versatile interface. The data encoded within the display format allows for an accurate monitoring of the phase of the primary coolant. This allows a user of the display to apply first principles in monitoring the plant. The cooling of the reactor core, a critical safety function, is a process function. Evaluating this function requires an assessment of the phase and state of the reactor coolant. Monitoring the coolant in terms of temperatureentropy space and the saturation properties of water and steam aids the operator in this important assessment. An operator does not need to understand the intricacies of thermodynamics to evaluate safety. Color coding and shape coding the states of water in the display serve to enhance an operator's pattern 
TABLE I

PROCESS VARIABLES NEEDED TO IMPLEMENT A CONSERVATION LAWS MONITORING STRATEGY

(Scope-PWR-Primary Coolant Loop)

\begin{tabular}{|c|c|c|}
\hline $\begin{array}{l}\text { Process Variables } \\
\text { (Control volume } 1 \text { ) }\end{array}$ & $\begin{array}{l}\text { Conservation } \\
\text { of Energy }\end{array}$ & $\begin{array}{l}\text { Conservation } \\
\text { of Mass }\end{array}$ \\
\hline \multicolumn{3}{|l|}{ Ideal Operation: } \\
\hline hotleg temperature, each loop & $\mathbf{x}$ & \\
\hline coldleg temperature, each loop & $\mathrm{x}$ & \\
\hline coolant flow, each loop & $\mathbf{x}$ & \\
\hline pump exit pressure, each loop & $\mathbf{x}$ & \\
\hline pump inlet pressure, each loop & $\mathbf{x}$ & \\
\hline pressurizer water level & & $\mathbf{x}$ \\
\hline subcooling of water, each loop & & $\mathbf{x}$ \\
\hline \multicolumn{3}{|l|}{ Normal Operation: } \\
\hline make-up flow rate & & $\mathbf{x}$ \\
\hline letdown flow rate & & $\mathrm{x}$ \\
\hline $\begin{array}{l}\text { water level, volume control tank } \\
\text { electrical energy, pressurizer }\end{array}$ & & $\mathbf{x}$ \\
\hline heaters & $\mathbf{x}$ & \\
\hline $\begin{array}{l}\text { pressurizer pressure and } \\
\text { saturation temperature }\end{array}$ & $\mathbf{x}$ & \\
\hline pressurizer spray flow & $\mathbf{x}$ & \\
\hline \multicolumn{3}{|l|}{ Abnormal Operation: } \\
\hline \multicolumn{3}{|l|}{ pressure, pressurizer } \\
\hline \multicolumn{3}{|l|}{ temperature, pressurizer } \\
\hline relief tank & $\mathbf{x}$ & $\mathrm{x}$ \\
\hline containment pressure & $\mathbf{x}$ & $\mathbf{x}$ \\
\hline containment temperature & $\mathbf{x}$ & $\mathrm{x}$ \\
\hline containment sump water level & $\mathbf{x}$ & $x$ \\
\hline reactor vessel water level & $x$ & $x$ \\
\hline charging flow rate & & $\mathrm{x}$ \\
\hline injection flow rate & & $\mathbf{x}$ \\
\hline $\begin{array}{l}\text { residual heat removal flow rate } \\
\text { residual heat removal heat exchanger, }\end{array}$ & $x$ & $\mathbf{x}$ \\
\hline primary coolant inlet temperature & $\mathbf{x}$ & \\
\hline $\begin{array}{l}\text { residual heat removal heat exchanger, } \\
\text { primary coolant exit temperature }\end{array}$ & $\mathbf{x}$ & \\
\hline refueling water storage tank level & & $\mathbf{x}$ \\
\hline emergency core cooling system level & & $\mathbf{x}$ \\
\hline Post-trip Reference Icon & $\mathbf{x}$ & $\mathbf{x}$ \\
\hline
\end{tabular}

PWR HEAT ENGINE

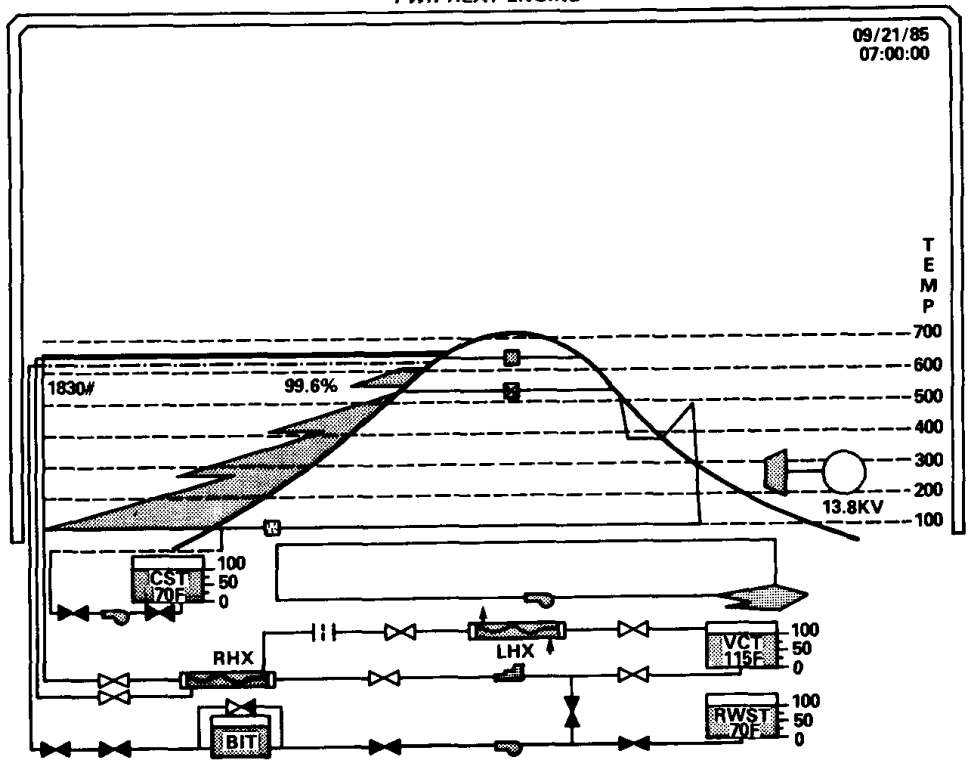

Fig. 4. Icon: PWR heat engine. 
recognition of unsafe operation. Furthermore, [9] contains examples of alarm coding (via symbols and color) of a modelbased display.

The process variables discussed for control volume 1 are necessary to monitor the ideal operation of the process. However, they are insufficient in a real world because of the assumptions made for this analysis. We now discuss these assumptions in the context of the conservation laws.

\section{B. The Normal Process Icon}

The primary coolant in a PWR needs make-up water to replace lost coolant mass due to leakages and letdown flow. During normal operation the flow rate of make-up water and the rate of coolant leakage are small. The net change in energy and mass of water in control volume 1 due to these sources is small and negligible. Thus as a first-order approximation the process variables identified in the preceding discussion serve to monitor the conservation laws of energy and mass. However, additional process data will serve to assure firstorder approximation. Make-up flow rate and letdown flow rate are useful variables since the difference in these flows indicates a net leakage flow. As long as the net leakage is small, then the identified variables are adequate to monitor the plant. Moreover, monitoring the source of make-up water and water sinks (containment sump level) completes the assessment of coolant mass. Thus monitoring water level in the chemical and control volume system and containment sump level is important. We delay the discussion of significant leakage of coolant from control volume 1 until later in the text.

The pipes in the coolant system are not perfect insulators. The coolant in control volume 1 loses a small amount of heat energy to the cold containment through the coolant pipes. Although the amount of heat loss is small, it does result in a small drop in coolant temperature. Thus the monitoring of energy distribution within the control volume is from coolant temperature. An accurate measurement of coolant temperatures will reflect heat loss from the piping system.

The pressurizer contains electrical heaters. The purpose of the electrical heaters is, when called for, to add sufficient heat energy to the water to boil the water and create vapor to increase pressure. Again, the amount of heat energy added is small relative to the energy the coolant receives in the reactor core. However, the electrical heaters deliver heat to the pressurizer region of control volume 1 . This heat energy boils water in the pressurizer, which results in saturated water and saturated steam in the pressurizer. Thus saturation temperature for pressurizer pressure is an important variable to monitor. Subcooling of the pressurizer water, a derived variable, is an alternative variable to monitor.

To reduce pressurizer pressure, cold water within control volume 1 serves as a spray to condense steam in the pressurizer. Since this action is internal to the control volume, no energy crosses the surface of the control volume. The heat of condensation heats the temperature of the spray water. This represents a redistribution of energy within the control volume, and thus spray flow is an important variable to monitor.

The coolant pumps perform work upon the coolant water within control volume 1 . The pumps are nonideal in perform- ance. The inefficiencies in the pumps result in heat addition to the coolant. This heat energy produces a small increase in coolant temperature. Thus temperature is an important process variable to monitor energy distribution within control volume 1.

At this point the application of the conservation of energy and the conservation of mass to control volume 1 served to identify important process variables to monitor plant performance. These process variables are useful in monitoring the plant during normal operation, and their use reflects a monitoring strategy based upon the conservation of energy and mass. A monitoring strategy based on these laws achieves an accounting of the energy and mass entering and leaving the control volume as well as distribution within the control volume. Table I identifies these additional variables to monitor normal operation of the process. These variables are necessary, but they are insufficient in monitoring performance during abnormal conditions, especially when the loss of the coolant cycle occurs such as during a pipe break.

\section{The Abnormal Process}

We discuss two specific types of significant leakage. In the first case a pressure relief valve opens to relieve the pressure within the control volume. In this case mass and energy leave control volume 1 through the open valve. It is not feasible to measure the rate at which mass and energy leave the control volume. However, one may measure the consequences of the leakage such as pressure and temperature in the pressure relief tank. Loss of the rupture disk in the pressure relief tank, pressure and temperature in containment, and sump water level are important variables to measure. As pressure within the pressurizer falls below the setpoint for the valve, the valve closes and the bulk of the coolant remains within the control volume. During the short time the valve is open, the process cycle within the coolant loop remained intact. After the valve closes, the cycle remains intact but with less coolant mass than before. The conservation laws for energy and mass still apply for the control volume as the control volume remains intact and the coolant system performs its functions.

The second case of a significant leakage is a pipe rupture within the coolant system. Another example of this type of leakage is a stuck-open pressure relief valve. In these cases a large quantity of coolant mass leaves the control volume. In the case of a severe pipe rupture the coolant loop ceases to function as a closed cycle. In a severe pipe rupture automatic initiation of the safety injection system adds coolant to the primary coolant system. This results in an input of coolant mass to control volume 1 . However, the coolant loop may cease to function as an effective cycle when, over a period of time, the bulk of the coolant flows out of a stuck-open relief valve, such as that which occurred at the Three Mile Island accident. A conventional application of the conservation laws for control volume 1 for these circumstances is difficult to achieve.

Measures of the consequences of the coolant leakage to containment are containment temperature, pressure, and sump water levels. With the operation of the residual heat removal (RHR) system, a coolant cycle exists to remove afterheat from the core. To monitor afterheat removal RHR coolant flow and 
inlet-and-exit RHR temperatures are important to assess. However, the control volume for this cycle is much larger than control volume 1 , and it is beyond the scope of this work.

There is a continuum of cases between the two specific cases discussed. An interesting example is a feed-and-bleed mode of operation, wherein the steam generators, because of the loss of feedwater and auxiliary feedwater, are ineffective as heat sinks and with tripped primary coolant pumps. Removal of core afterheat is from the periodic opening of the relief valves and the release of steam and possibly liquid-phase water from the pressurizer. When the valves are opened, steam is released, coolant pressure drops, and water flashes into steam, removing the heat of vaporization from the water and thereby cooling it. Thus heat and mass leave control volume 1 as steam flows through the open valves. The highpressure charging system pumps water into the reactor vessel. Control volume 1 remains intact; however, a batch process for heat removal exists rather than a cycle. The conservation laws are applicable, but it is difficult to apply them directly. The reason for this is because a direct measure of mass and energy leaving the control volume is unavailable. Reactor water level and pressurizer water level provide some indication of the mass of liquid-phase water within the control volume. Pressure and water temperatures provide an indication of the energy stored in the water. With a closed relief valve these variables increase with time as the control volume continues to receive heat energy from the reactor. Removal of heat from the control volume occurs when the relief valve opens.

Because of the large number of variations in leakage of mass, it is extremely difficult to know when the conservation laws for control volume 1 cease to apply. This makes it difficult to adapt the conservation laws as a general monitoring strategy by a human operator. The number of variations for mass leakage becomes so large that it is impossible to remember them all. This problem is overcome with the display of a reference process icon in conjunction with the actual process icon. The reference icon serves as the setpoint for the process and embodies the conservation laws. The reference process icon also serves as a tool to diagnose the cause of deviations in plant performance. A discussion and illustration of a reference process icon for afterheat removal follows.

\section{The Reference Icon}

The problem of monitoring the plant for afterheat removal is overcome with a reference process icon depicting normal afterheat removal. A post-trip reference process icon represents normal operation of the plant following a trip. All plant trip systems are normal and operable. The reference process icon encodes the conservation of energy and mass for normal afterheat removal. Construction of a post-trip reference process icon may occur from existing trip data for a plant. By definition the distribution of energy and mass in the reference process icon represents a normal heat removal cycle and depicts safe operation. The reference icon represents a stabilized plant after the trip. The rate of afterheat produced in the reactor is equal to the heat lost by the coolant to the surroundings (basically, condenser to the environment). Fig. 5 illustrates a reference icon for part of the heat engine. Finally, to complete the picture, a time-variant reference icon could serve as a setpoint during a controlled cooldown of the plant.

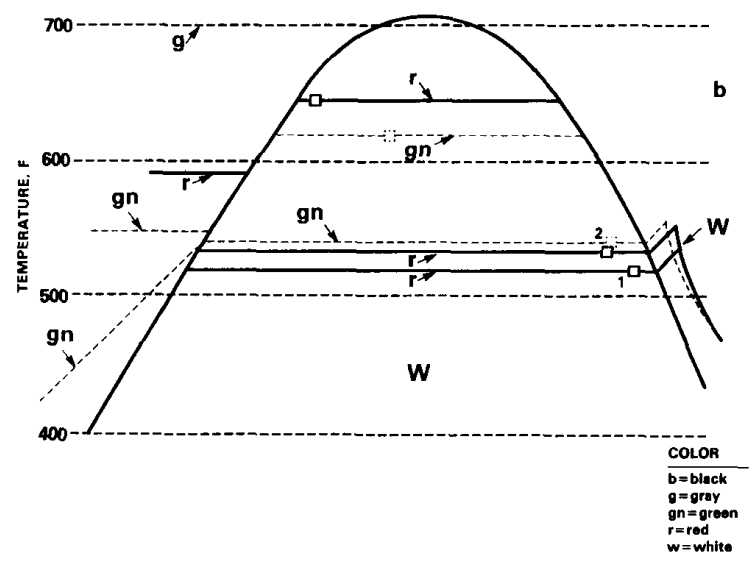

Fig. 5. Davis Besse, 06/09/85, 01:53:00 AM. Post reactor trip with abnormal process coded red and reference icon coded green.

There is no meter to measure the afterheat produced in the core, which is similar to a flux meter when at power. Inherently, the reference icon contains the proper coolant flows and temperatures. By displaying the reference heat cycle and the actual heat cycle simultaneously, significant deviations between the two are immediately observable. By real-time monitoring and analysis of these differences in terms of the conservation of energy and mass, an operator should be able to identify quickly where storage or the release of heat and mass from control volume 1 is occurring. This analysis should identify impedances to the heat cycle. This will help the operator to focus upon the integrity of the cycle and to determine if a normal or abnormal event is underway.

The difference between the reference process icon and the plant's process icon will serve to identify the loss of a steam generator. An example of this specific case is in [8]. Fig. 5, replicated from [8], illustrates the reference process icon and the plant's process icon. From this figure we see that the steam generators are empty of water. The primary coolant is absorbing the afterheat from the reactor, resulting in abovenormal water temperature and pressure. Also, we note that the pressurizer is almost full of water because of the less-dense heated water. A red color code serves to identify the abnormal portion of the process within the plant. This color serves as a means to encode alarms within the process. Also, note that the color codes for the reference icon are green, which signifies a normal state. Furthermore, the reference icon should serve as a significant aid since no sensors exist to measure the magnitude of the afterheat being generated in the reactor core. In this context the reference icon shows the encoded afterheat in terms of temperatures, coolant flows, and coolant mass within the various coolant loops for a stabilized plant shortly (minutes) after reactor trip.

The upper right-hand corner of Fig. 5 is the place to locate data such as date, current time, and elapsed time, but these are not illustrated. The elapsed time after trip is important data. If the process icon is trending towards the reference icon within a few minutes after a trip, then it is most likely a normal trip. On the other hand, if the process icon is trending away from the reference icon within a few minutes after a trip, then an 
abnormal trip is in progress. This data serves to alert the operator that action may be necessary to restore the plant to normal operation.

Monitoring the emergency sources of water for the primary coolant system completes the assessment of coolant mass during abnormal operation. Thus the refueling water storage tank level, injection flows, charging flow, and the water levels in the emergency core cooling system are important variables to monitor. Table I lists these additional variables needed to monitor the primary system's process during abnormal operation. Table I also identifies the post-trip reference icon as a valuable set of variables.

Encoding of abnormal levels of radiation is also feasible within the process icon. Reference [2] discusses and illustrates this point for an icon of the Ginna steam generator tube rupture. A discussion of the general strategy for monitoring radiation is beyond the scope of the current work.

One way to look at the reference icon is to consider it as the expert's mental model used in evaluating the goals of plant operation. The reference icon embodies the conservation of energy and the conservation of mass in the ideal operation of the heat engine cycle. Furthermore, the reference icon presents the correct structure of the process functions and variables within the heat engine cycle. In this context the display of the reference icon also serves to externalize a human's mental model of the ideal process. This eliminates the need to recall it from long-term human memory.

In theory it may be possible to construct a reference heat removal cycle to show afterheat removal during operation of the engineered safeguard systems. A comparison of the actual heat removal cycle with the reference heat removal cycle provides the operator with a rapid assessment of the functional performance of the heat removal cycle and the engineered safeguard systems. An analysis of operational data should help to determine feasibility of such a reference icon. Details for this subject are beyond the scope of this discussion.

A reference process icon is also feasible for operation at design power. The reference process icon embodies the correct distribution of energy and mass for steady-state operation at design reactor power. In other words it reflects the conservation of energy and the conservation of mass during normal operation. The reference icon serves as a setpoint for normal operation. Significant deviations by the actual process icon from the reference icon would indicate anomalies within the plant. A real-time analysis by an operator of the deviations in the distribution of mass and energy should aid in diagnosing and locating the cause of the anomaly.

A reference icon at design power encodes optimal operation. By encoding optimal operation it serves as a setpoint for operators in running the plant. The reference icon encodes facts about plant operation. For example, the work performed by the turbine is the electrical energy produced by the electrical generator. For most PWR's the turbine work consumes about one-third of the reactor heat produced. The remaining two-thirds of the reactor heat leaves the heat engine through the condenser as heat to the environment. Fig. 4 illustrates a process icon for a PWR at design power. It illustrates the operation of the heat engine from heat source, the reactor, to heat sink, the environment. Fig. 4 also illustrates the plant systems that supply make-up water to the process. The data in Fig. 4 could serve as a reference icon for use by the operator.

The use of a system-process icon adds a new dimension to the display. Fig. 6 illustrates a post-trip operating mode of a PWR. The condition illustrated shows the engineered safeguard systems as water sources for the reactor core. These consist of the accumulators (ACUM), the upper head injection system (UHI), the refueling water storage tank (RWST), and the residual heat removal system. The condensate storage tank (CST) is the water source for the steam generators. This system-process icon presents some of the plant systems that act upon the process. The systems that provide emergency water to the process and the systems that contain coolant leakages from the process are also present (the pressure relief tank and the containment sump). Thus the consequences of leakages from the process are viewable in one display format.

As shown in Fig. 6 the distribution of coolant mass is in storage tanks within the process coolant loops and in relief tanks and sumps. The goal is to maintain an adequate mass of coolant within the process loops to sustain normal operation of the plant. However, in measuring the amount of coolant in a coolant loop, water level is an indication of volume. Transients in a plant, wherein the average temperature of the coolant changes, will result in a change in pressurizer water level. Also, when the coolant in the reactor is saturated water, then steam voids may exist. Thus it is difficult to monitor mass solely from pressurizer water level.

In monitoring primary coolant mass the state of the water must be known. When the water outside of the pressurizer is at or near saturation, then steam voids may exist in the reactor coolant loops. When subcooling of the water is small, it is also necessary to monitor reactor vessel water level in assessing coolant inventory. Furthermore, it also helps to monitor water sources, flow rates from these sources, temperature and pressure in containment, and water levels in the containment sump and the pressurizer relief tank. In doing so the operator monitors liquid-phase water but is unable to monitor the volume of steam in the primary coolant system. However, monitoring water sources and sinks, in addition to the data within the coolant system, provides a composite of mass distribution. Thus the system-process icon must show water level in the containment sumps and relief tanks in addition to temperature and pressure in containment. The temperature and pressure in containment are key indicators to identify and monitor abnormal operation.

For normal operation of containment at design power the bulk temperature of the air in containment is around $110^{\circ} \mathrm{F}$. The average normal pressure in containment is one to two $\mathrm{lbf} / \mathrm{in}^{2}$ below atmospheric pressure. During a major leakage of primary coolant from the plant to containment, the average temperature of the containment will then rise to greater than $200^{\circ} \mathrm{F}$. This is not surprising since the saturated temperature of saturated steam at atmospheric pressure is $212^{\circ} \mathrm{F}$. For small releases of steam from the plant to containment, the steam will condense to water because of the heat sinks within containment. Thus monitoring containment temperature and pressure, in addition to water levels in sumps and relief tanks, allows for monitoring the leakage of mass from the primary coolant 


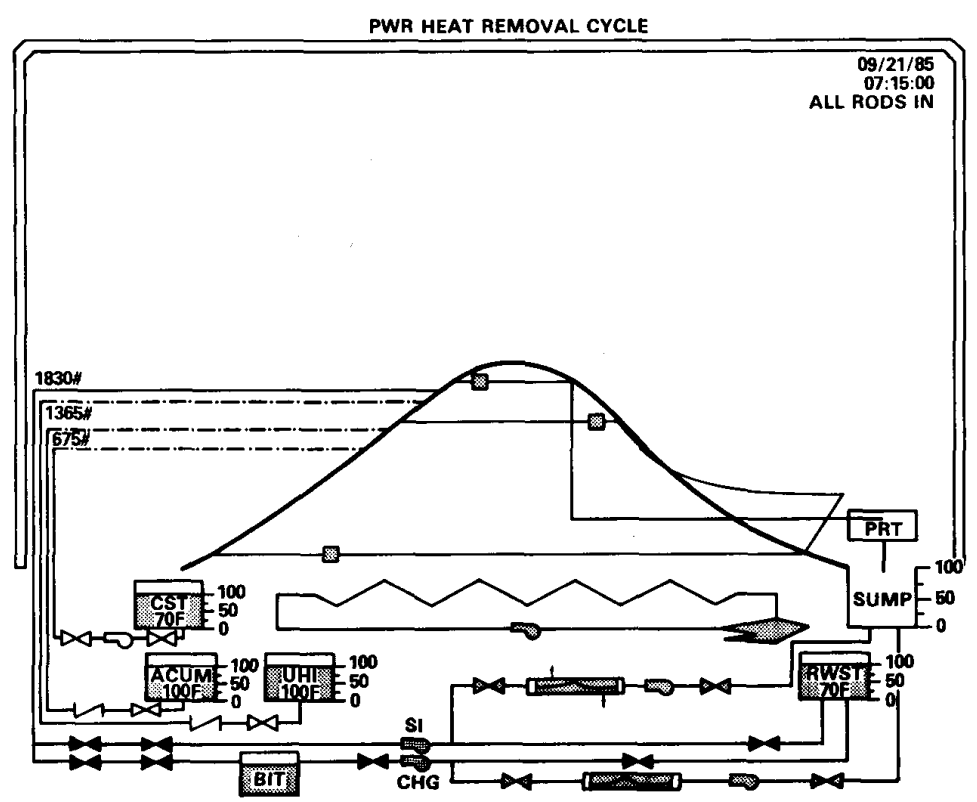

Fig. 6. Icon: PWR heat removal cycle; no aux feedwater.

system in a PWR. To limit the scope of this discussion we do not discuss the heat sinks within containment.

The distribution of mass is the fundamental basis used to identify leaks in the system, given that sufficient data is available to the user. One method is a reference heat cycle that displays the nominal coolant levels (steam generators, pressurizer, hotwells, and containment sump). By definition the reference cycle conforms to the conservation of mass. With a real-time comparison between the measured levels and the reference levels, an operator identifies the differences in mass distribution. Major differences in levels should serve as key indicators to the cause of a leakage. An operator must also consider the temperatures within the actual cycle and the subcooling of the water in comparing performance to the reference cycle. During accidents saturated steam and water may exist in the reactor core and coolant loops. A comparison of the accident icon with the reference icon easily identifies the loss of subcooling.

An inadequate amount of coolant in the primary coolant system will result in unsafe operation of the reactor. When the coolant fails to remove the heat generated in the reactor core, the fuel system then absorbs the heat and its temperature rises. If allowed to continue without adequate coolant to remove the heat, the fuel eventually melts. The goal is to avoid operation with insufficient coolant by maintaining liquid-phase water in the reactor core. The engineered safeguards such as the emergency core coolant system and the residual heat removal system achieve this goal.

Plant systems contain and control the process. A failure of a plant system may result in significant impact upon the process. The use of the conservation of energy and the conservation of mass as the basis of human monitoring of a plant with a modelbased display-type interface aids diagnosis. The monitoring of system variables such as control system variables would also help in diagnosing a failure. An analysis of plant systems would identify the important variables to monitor.
Table I summarizes the variables identified as important from the preceding discussion. These variables are process variables resulting from the application of the conservation laws of energy and mass to the primary coolant of a pressurized water reactor. Furthermore, the process variables are in sets for ideal operation, normal operation, and abnormal operation, which reflects the discussion. With the total set of process variables one should be capable of monitoring the process within the primary coolant system of a pressurized water reactor by using the conservation laws. However, a total monitoring strategy for the primary coolant system requires additional variables to evaluate the systems that act upon the primary coolant. For example, the coolant pump speed and the status of relief valves are also important system variables. One must also analyze all of the systems that act upon the primary coolant to identify important system variables to monitor. Only after the identification of these system variables may one optimize the total list of process and system variables and eliminate unnecessary redundant variables. Finally, the illustrations in this paper do not contain all of the variables in Table I. One reason for this is that the author did not have the benefit of an analysis based upon the conservation laws.

In summary, the conservation laws of thermodynamics for energy and mass provide a sound basis for monitoring the plant for normal and abnormal operation. The use of a reference icon allows a user of the display to compare actual plant performance with a setpoint for operation. The diagnosis of significant deviations from the reference icon proceeds from first principles with respect to energy and mass.

\section{The Human Operator}

The recent work of Rasmussen and Vicente [5], [6] stress two important concepts. They are the externalization of mental models and the recall paradigm. They deal with the design and evaluation of interfaces. A short discussion of each concept follows, and additional details are in the references. 


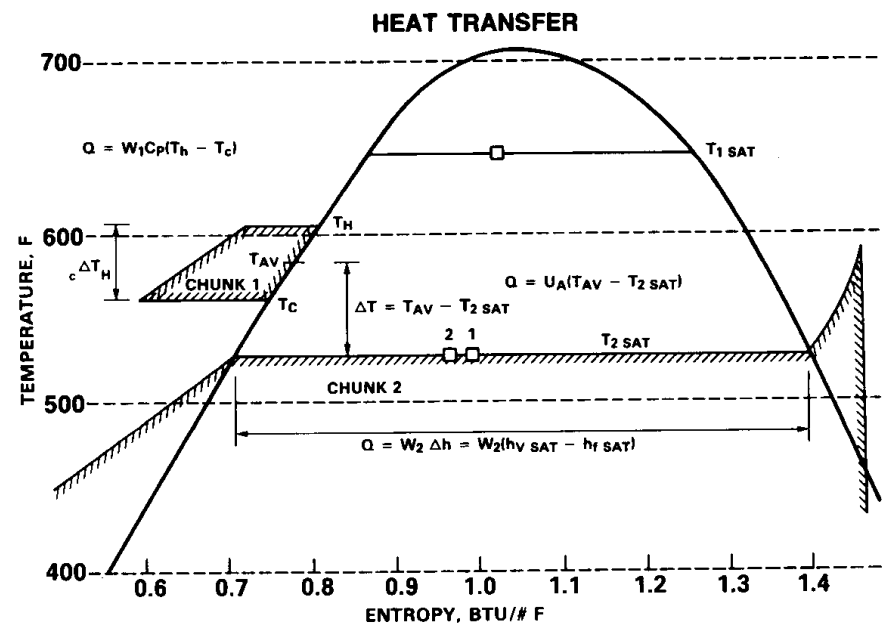

Fig. 7. Illustration of chunking.

Externalization of a mental model is a mapping of the world from measured variables to form and display a model of the world (a model-based display). The system-process icon represents a mapping of the plant operations from sensor data and the use of stored rules. The mapping of individual process data such as temperatures, pressures, and coolant levels into a process cycle automates the tasks of collecting and structuring the data for the operator. The Rankine cycle serves as a means to structure the data. This form of the data illustrates the heat transfer functions within the coolant loops. It also illustrates the heat engine cycle. Finally, this form of the data facilitates a monitoring strategy based upon the conservation of energy and the conservation of mass. All of these features serve to aid the operator in monitoring plant operations and to diagnose faults when they occur. These features also aid in the assessment of the goals of operation: to produce electrical energy economically and safely. In summary, the goal is to design interfaces that support problem solving tasks and functions by humans.

The recall paradigm discussed in [6] is a methodology developed by DeGroot to illustrate chunking by humans. In discussing the use of the recall paradigm, [6] states

A good interface should reveal the properties of the world, and since the person would already have this knowledge in his mental model, it should be very easy for him to interpret the state of the world with such a transparent interface. In order to evaluate interface transparency in this way, we need a methodology for measuring the degree of fit between the subject's "normative" mental model and the interface.

This reference also discusses and interprets DeGroot's experiments, which illustrated the performance (memory recall in terms of accuracy and speed) of chess experts versus chess novices when presented with a chess problem.

Reference [6] also discusses the recall paradigm in terms of the theoretical aspects of chunking. This discussion identifies two theoretical aspects of chunking, which are

1) the expert's familiarity with the perceptual characteristics of the domain, and

2) the meaningful aspects arising from the expert's hierar- chical knowledge representation of domain goal structure; chunking is primarily due to the fact that stimulus is more meaningful to the expert than to the novice.

In short, the expert's superior recall ability and performance is the result of knowledge stored in memory. Reference [6] also discusses the limitations and proposed uses of the recall paradigm as a tool to evaluate interfaces.

Fig. 7 supports the process of chunking and the meaningful aspect of chunking. It replicates a figure from [4]. The data in Fig. 7 illustrates a process icon for the primary coolant system and the secondary coolant system of the Davis Besse Plant operating at 91 percent of design power (see [4] for details). Within the process icon, chunk 1 is a polygon located to the left of the saturated water line between $560^{\circ} \mathrm{F}$ and $610^{\circ} \mathrm{F}$. The data within this chunk consist of hotleg temperature $T_{\mathrm{h}}$, coldleg temperature $T_{\mathrm{c}}$, and the amount of subcooling (the horizontal distance to the left of the saturation curve) for these coolant temperatures. Chunk 1 encodes the temperature and subcooling status of the coolant mass within the primary coolant loop exclusive of the pressurizer coolant. Additional details on the individual process variables within chunk 1 are in [2].

Chunk 2 in Fig. 7 contains data from the secondary side of the steam generators. This data consists of subcooled water in the steam generators, the boiling process in the steam generators (from saturated water to saturated steam), the water level in the steam generators, the superheating of the steam, and part of the expansion of the steam in the turbine. Additional details on the individual process variables in chunk 2 are in [2].

The physical position of chunk 1 to chunk 2 in Fig. 7 represents the heat transfer coupling between the primary coolant system and the secondary coolant system. The bulk of the heat transfer from the primary coolant system to the secondary coolant system boils the secondary coolant, converting it from a saturated liquid to a saturated vapor. Generally, a small amount of the heat transfer from the primary system to the secondary system goes to preheating 


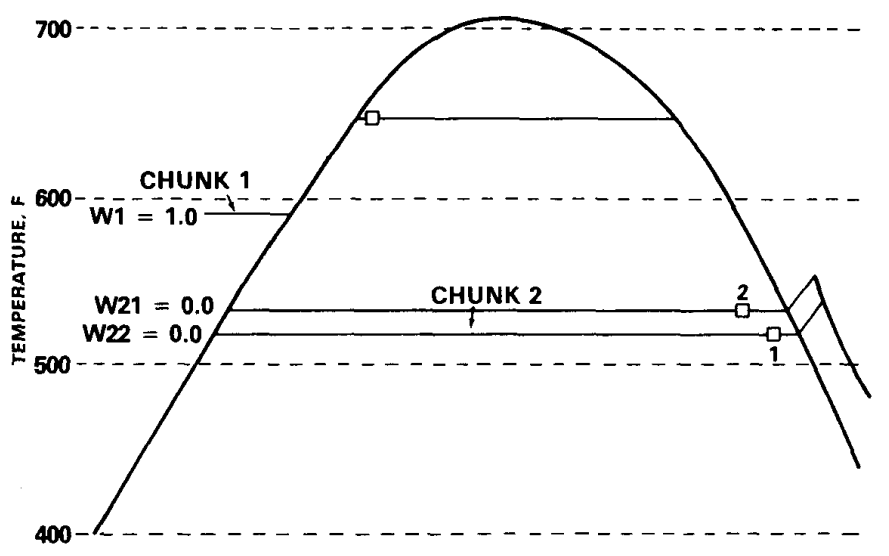

Fig. 8. Davis Besse, 06/09/85, 01:53:00 AM. Post reactor trip.

subcooled coolant to a saturated state. Also, a small amount of heat goes to superheat the saturated vapor.

An equation that describes the bulk of the heat transfer between the primary coolant and the secondary coolant is

$$
Q=U A\left(T_{\mathrm{av}}-T_{2 \mathrm{sat}}\right)
$$

where

$Q$ heat transfer rate,

$U A$ overall heat transfer coefficient,

$T_{\text {av }}$ average temperature of the primary coolant,

$T_{2}$ sat saturation temperature of the secondary coolant.

This heat results in boiling of the saturated secondary coolant described by equation

$$
Q=W_{2}\left(h_{\mathrm{vsat}}-h_{\mathrm{fsat}}\right)
$$

where

$W_{2}$ flow rate of the secondary coolant,

$h_{\text {fsat }}$ enthalpy of the saturated coolant fluid (water),

$h_{\text {vsat }}$ enthalpy of the saturated vapor (steam).

The heat lost by the primary coolant in the steam generator is

$$
Q=W_{\mathrm{l}} C_{\mathrm{p}}\left(\mathrm{T}_{\mathrm{h}}-T_{\mathrm{c}}\right)
$$

where

$W_{1}$ primary coolant flow rate,

$C_{\mathrm{p}}$ coefficient of specific heat, constant pressure,

$T_{\mathrm{h}}$ hotleg temperature,

$T_{\mathrm{c}}$ coldleg temperature.

Also, the average temperature of the primary coolant is simply

$$
T_{\mathrm{av}}=\left(T_{\mathrm{h}}+T_{\mathrm{c}}\right) / 2 .
$$

Based on the bulk heat transfer these equations reflect the conservation of energy. The magnitude of the term $T_{\mathrm{av}}-$ $T_{2}$ sat is the key term that evaluates the coupling between the primary and secondary coolant system. This is the term that relates chunk 1 to chunk 2 in Fig. 7. The magnitude of $T_{\mathrm{av}}-$ $T_{2 \text { sat }}$ in Fig. 7 is normal for the operating conditions of the plant. Also, the hotleg temperature of the primary coolant is higher than the maximum temperature of the superheated steam. Finally, the coldleg temperature of the primary coolant system is higher than the saturation temperature in the steam generators. This is consistent with heat flow from a heat source at high temperature, the primary coolant, to a heat sink at a lower temperature, the secondary coolant. These facts illustrate the meaning and physical relationship between chunk 1 and chunk 2 . The discussion suggests a need for a chunk analysis to design a display. In the case of a heat engine cycle, the chunks may easily be the process functions within the cycle.

Fig. 8, replicated from [4], illustrates an abnormal post-trip state of the plant. In a normal post-trip condition the magnitude of the term $T_{\mathrm{av}}-T_{2 \text { sat }}$ is only a few degrees. This is because of the high heat transfer coefficient, the small amount of afterheat in the reactor core, and the adequate coolant flow in the secondary side of the steam generator. However, the data in Fig. 8 represents a condition wherein there is no coolant flow ( $W_{21}=0.0$ and $W_{22}=0.0$ ) in the secondary side of the steam generators. The primary coolant appears to be isothermal and much hotter than the inadequate coolant in the steam generators. The primary coolant flow $W_{1}=1.0$ is at the design rate. The term $T_{\mathrm{av}}-T_{2 \text { sat }}$ is large for these operating conditions, thereby indicating that the primary coolant is not thermodynamically coupled to the secondary coolant. The afterheat produced by the reactor is being absorbed by the coolant and the structure of the primary coolant system, resulting in a heatup of these items. Thus the status of the reactor core becomes evident from the relationship between chunk 1 and chunk 2. Also, this condition of the primary system results from the conservation of energy within control volume 1 upon loss of the steam generators as heat sinks.

The discussion illustrates how the process icon could support the process of chunking in humans. Other examples of chunks exist in Fig. 4 such as the data associated with the heat transfer between the condenser and the environment. Reference [6] promotes the use of the recall paradigm as a methodology to measure the existence of chunking in humans. The results from the experimental use of this methodology should prove interesting.

The discussion on chunking in association with the data in Figs. 7 and 8 suggests the use of rules in interpreting the chunks. For example, Fig. 7 illustrates normal plant operation 
at 91 percent design power, whereas Fig. 8 illustrates abnormal post-trip operation. The interpretation of the chunks depends on the power level of operation and the coolant flow rates in the plant. A formal definition of these rules could serve as the basis of an expert system to aid the operator in evaluating plant status.

The role of a model-based display is to present data in a form that facilitates semantic interpretation by chunking data to promote memory recall in a user. By chunking data in a display, a trained user's cognitive workload in processing and interpreting the data is minimal. This minimizes the impedance of the interface by maximizing the dialogue and communication from the plant to the user. A model-based display satisfies this role when the model chunks related data. Computer graphic segments serve as chunks in forming a model-based display. Initial operational results with a process icon in an experimental reactor substantiate these concepts [7].

The system-process icon discussed and illustrated in Section II is a real-time synthesis of plant operations. The process portion of the icon consists of the heat engine cycle based upon measured process variables. The system portion of the icon consists of system mimics with the status of components updated from measured system variables. The processing and integration of raw sensor data into a model of plant operations aids a human operator in monitoring the plant. It also allows the operator to monitor on the function and goal level rather than the individual process variable level. These features of the display should aid the operator in decisionmaking and problem-solving tasks during abnormal operations.

The thermodynamic laws of the conservation of energy and the conservation of mass identify a basic monitoring strategy for human operators. The process never fails; however, the coolant may change state such as from a liquid phase to a vapor phase. Plant systems contain and control the process, and components within systems do fail. Failure of plant components and systems will impact the process. A modelworld interface based upon the process and plant systems should serve as a cognitive aid to operators in diagnosing failures in plant systems.

One common use of computer-driven cathode-ray tubes is to trend and display process variables in the plant. The trend of process data presents the dynamic aspects of the process. With the trend of a process variable an operator monitors recent performance of the variable. The trend of a process variable serves as an operator aid in monitoring plant transients and in diagnosing faults in a plant. The trend also provides a basis for predicting the short-term future values of the variable, which aids the operator in planning future actions. The trend display synthesizes perfect recall of the process variable's history by a human expert.

By using a video tape recorder (or an optical disk) to realtime record plant operations from a model-based display, one achieves a function trending capability. A fast replay of the tape presents the trend of process functions. This replay serves as an aid in diagnosing plant transients and in helping to identify faults in plant systems. The monitoring of trends in process functions provides a high-level overview of operations. This should aid operators in detecting and diagnosing abnormalities in the plant. Also, the function trend consists of a composite of the trend of many process variables. An attempt by most humans to recall this quantity of data in realtime would result in failure. In summary, a fast replay of a video tape serves as a memory aid.

\section{The Reference Icon as a Setpoint}

There are other advantages of the system-process icon. A monitoring strategy based upon first principles is feasible. The first principles consist of the conservation of energy and the conservation of mass. The reference icon displays and identifies the ideal state of the process. The reference icon aids human users in evaluating the conservation of energy and the conservation of mass within the plant. Operation with significant deviations from the reference icon may indicate failures within plant systems. Under these circumstances the conservation laws are useless since data to evaluate the laws are unavailable. However, one may monitor and diagnose the consequences of the event from data within the systemprocess icon for the plant. Also, the data within the systemprocess icon will help to support the evaluation of hypotheses formulated by operators in diagnosing an event.

The reference icon and the actual process icon allow a human to monitor deviations from ideal operation. The reference icon for post-trip operation serves a useful function as setpoint for afterheat removal. It provides the operator with a clearly defined goal for plant operation. Significant deviations from this goal are the cause for operator concern and possible corrective action.

Within the context of this discussion Fig. 9 contains a model of the human-process control-display interface for a plant. We assume that the interface is computer-based with input devices of keys and mice and output devices of cathode-ray tubes. Operator input at the interface results in modifications to openand closed-loop control systems within the plant. An interface display with the reference icon and the system-process icon provides plant status. The model allows the human operator to perform skill, rule, and knowledge-based behavior upon interacting with the interface.

The model of the operator in Fig. 9 presents the human as an information processor. Rasmussen [9], [10] defines typical information processing activities consisting of the following:

1) ACTIVATION; detection of need for data processing,

2) OBSERVE information and data,

3) IDENTIFY present state of system,

4) INTERPRET consequences for current task,

5) EVALUATE performance criteria,

6) DEFINE TASK; select appropriate change of system condition,

7) FORMULATE PROCEDURE; plan sequence of actions, and

8) EXECUTE; coordinate manipulations.

Additional details on these activities are found in the references.

The reference icon serves the role of setpoint for human performance (see Fig. 9). Operation with significant deviation from this setpoint may require operator intervention to correct a disturbance. The decision for human intervention may result 


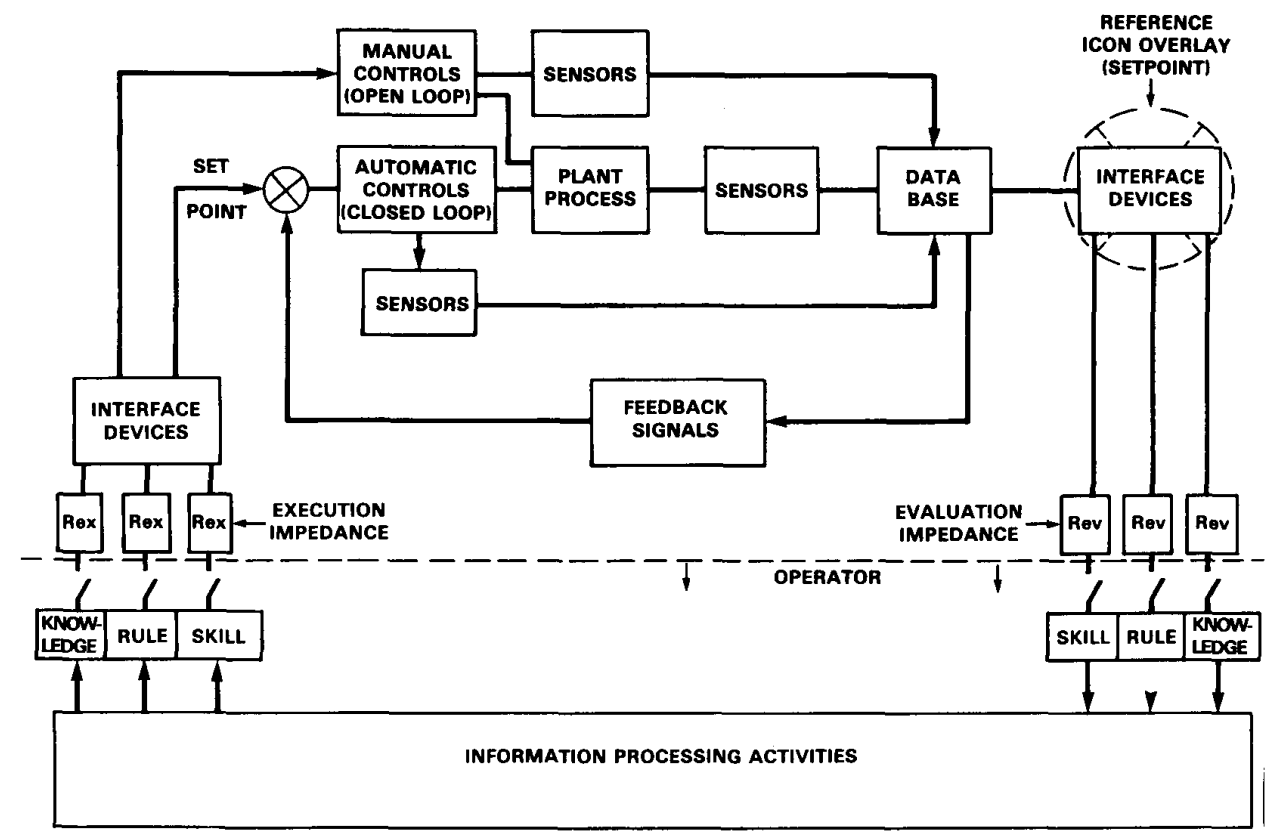

Fig. 9. Human operator-process control interface model.

from knowledge-based behavior such as diagnosing a fault in the plant. The decision may also result from rule-based behavior such as executing a procedure or skilled-based behavior such as acknowledging an alarm.

An impedance exists at the interface for each type of human behavior. Evaluation impedance is a measure of the difficulty experienced by a user of an interface in performing an assigned function or task based upon the use and interpretation of displayed data. Execution impedance is a measure of the difficulty experienced by a user of an interface in initiating or executing an assigned function or task based upon the devices available. For example, in evaluating the status of the plant the impedance of an interface consisting of individual instruments or displays of process parameters is higher than an interface consisting of a process icon. With control boards consisting of individual instruments the operator must gather and integrate several pieces of data to mentally formulate chunks 1 and 2 illustrated in Fig. 7. This mental process must also consider the properties of water in order to evaluate the subcooling of the primary coolant. This is a difficult task under stress because most humans do not store steam table data in memory. Finally, a human evaluates the chunked data to assess the thermodynamic coupling between the primary and secondary system. The impedance of this type of interface is high because of the resources that a human must employ to fully complete the task. Part of this impedance may be overcome through the use of procedures, which are written rules that structure and formalize the described thought process. Fig. 7 illustrates an alternative type of interface with lower impedance. As a final note, the use of the term impedance in this discussion appears to be semantically similar to the term transparency in [7] (see also the related discussion in Section III).

One means of reducing evaluation impedance in an interface is to provide the human user with decision support aids. For example, the use of an expert system to filter alarms serves to focus the operator's attention on the most important alarms. Another example is to use an expert system to diagnose the cause of a plant disturbance from measured data and then to identify a procedure for operator use. In some events, it may not be possible for an expert system to identify a response procedure. In these circumstances the operator must formulate a response plan (knowledge-based behavior) and execute it to restore the plant. Computer-based decision support aids to assist operators in formulating a response plan would be useful during these events.

Another feature of the model in Fig. 9 is the engagement of the operator in running the plant. Fig. 9 illustrates the human operator as disengaged, which does not reflect reality. In reality, with a plant at steady-state, an operator will always be monitoring plant performance but not necessarily providing input to the plant. A closing of the switch associated with skillbased behavior of the operator at the display interface in Fig. 9 reflects this case.

\section{INSIGHTS ON IMPLEMENTATION}

A few words on implementation of the display are necessary. One needs to employ expert system technology to develop a robust model-based display. The process icon reflects the use of a knowledge base of process functions and the heat engine cycle. The pertinent process functions are

1) heating of a single-phase fluid,

2) cooling of a single-phase fluid,

3) boiling,

4) condensing,

5) compression (pump work)

6) expansion (turbine work), 
7) throttling, and

8) blowdown.

The temperature-entropy properties of water are also part of the knowledge base. The data associated with each of the process functions listed form a chunk, which may then be represented graphically in a display.

An inference engine for the process icon utilizes rules and plant data to identify and link process functions to display the heat engine cycle. For example, during normal operation of a PWR at power a model-based display illustrates turbine work as part of the cycle within the secondary coolant loop (see Fig. 4). However, during normal post-trip operation the display of a throttling process illustrates the flow of the secondary coolant through the turbine bypass valve (see Fig. 6) rather than the turbine. The designer of the process icon must be careful to chunk data appropriately for display to support meaningful interpretation of the data by the human operator.

In a system-process icon one requires a knowledge base on plant water resources. These water resources consist of normal-process make-up water systems and emergency water systems. An inference engine serves to control the display of these systems and their interaction with the process. For example, during normal operation of the plant the systemprocess icon contains the make-up water systems for the primary and secondary coolant systems (see Fig. 4). However, during abnormal operation when the plant uses the engineered safeguard systems, the system-process icon contains these systems (see Fig. 6). The control laws and the initiation logic for the engineered safeguard systems serve as part of the inference engine. Properly structured, an inference engine contains rules used by an expert operator in monitoring the plant. However, the development of these rules does require plant specific knowledge.

\section{ConClusion}

In summary, the conservation laws of thermodynamics for energy and mass are the basis for monitoring the plant during normal and abnormal operation. The use of a reference icon allows a user of the display to compare actual plant performance with a setpoint for operation. The diagnosis of significant deviations from the reference icon proceeds from first principles with respect to energy and mass.

The abstract concept of a control volume served as an important tool in the analysis discussed. The use of this tool served as the basis for applying the laws of conservation of energy and mass. The scope of the analysis is for the thermodynamic process within the primary coolant loop of a pressurized water reactor. The abstract concept of a control volume takes physical dimensions with the coolant volume identified by the primary coolant system. With the flexibility of computer-driven interfaces, a designer may implement displays to support a monitoring strategy based on the conservation laws.

In this discussion the conservation laws for energy and mass served as the theoretical foundation of the system-process icon. The discussion illustrates the use of these laws for a control volume consisting of the primary pressure boundary within the primary coolant loop of a pressurized water reactor. Analysis of the control volume with these laws serves to identify important process variables. Thus the conservation laws serve the human operator as a feasible tool for monitoring plant operations. The use of a reference process icon embodies the conservation laws, allowing the human operator to compare the plant's process icon with a setpoint for operation. In summary these features of the system-process icon allow an operator to evaluate the following goals of operation:

1) maintain the coolant mass inventories in the process loops, and

2) sustain the heat transfer process from the source (the reactor) to the heat sink (the environment) within the heat engine cycle (the process).

This work also discusses a model of the human-process control interface. The system-process icon serves as a modelbased display of plant operations. In this role it is an externalization of a user's mental model of the plant. The structured form of the data in a model aids human users in the semantic interpretation of the plant's state. Furthermore, encoding process and system alarms within the display also aids human users in the detection and diagnosis of plant faults.

The training of operators in the use of this display should help them to chunk the basic thermodynamic principles into long-term memory. However, a few basic facts about water, supported by perceptual codes in the display, help to simplify the operator's task of evaluating the safety status of the plant. The use of the same display in the control room then serves to activate the recall of principles from human memory and application of them in operating the plant.

The illustrations in this work are for a pressurized water reactor. However, the logic to explain and illustrate the model-based display also applies to other facilities that employ a Rankine cycle. For example, a fossil power plant employs a Rankine cycle as its basic heat engine.

\section{APpEnDix I}

\section{Heat Engine Notes}

Thermodynamics is a complex subject. The design of computer-based interfaces for large heat engines must begin with a reasonable knowledge of thermodynamics. A nuclear power plant is a large heat engine. This discussion identifies a key source of information that contains fundamental and precise definitions and concepts for thermodynamic terms.

Reference [11] is the source of the definitions. We identify only terms and page locations here:

conservation of mass: $\mathrm{p} .12$

control volume: p. 12

property: p. 24

process: p. 24

state: p. 24

cycle: p. 24

equality of temperature: p. 24

temperature: p. 24

zeroth law of thermodynamics: p. 25

work: p. 25 
first law of thermodynamics: p. 27

internal energy: p. 27

heat: p. 27

first law for a cycle: p. 28

heat engine: p. 29

system: p. 11

first law for a control volume: p. 37

second law of thermodynamics: p. 30.

APPENDIX B

Man-Machine Notes

Icon: An image.

Process Icon: An image of the process within the plant. In this report the process icon is an image of the heat engine cycle within the plant.

System-Process Icon: An image of systems and the process within the plant. In this report water make-up systems, emergency water systems, and the heat engine cycle compose the system-process icon.

Reference Process Icon: An image of the process that characterizes the desired state of the plant operation.

Mental Model: A model of the plant a human uses in thought processes to predict output from plant systems and the heat engine cycle based on inputs to plant systems and the heat engine cycle. In short it is a human's qualitative transfer function for plant systems and the heat engine cycle.

Impedance: A resistance.

Evaluation Impedance: A resistance in the dialogue and communication between a display interface and a human operator while monitoring the plant.

Execution Impedance: A resistance in the selection and initiation of a control function while operating the plant.

Mapping: A transformation of data from one form to another.

Chunking: An integrated set of related meaningful data stored in human memory.

Synergy: A measure of the cooperation between two dissimilar entities, e.g., a human operator and a process control board.
Object: A computer-generated graphic element that may be acted upon by the human user.

\section{ACKNOWLEDGMENT}

The author wishes to acknowledge the technical contributions of Mr. Richard Lindsay of Experimental Breeder Reactor II, Dr. Jens Rasmussen of Riso Laboratory, and Mr. Kim Vicente of the University of Illinois at UrbannaChampaign. The rich technical discussions and constructive comments by these gentlemen on drafts of this work were extremely useful to the author.

\section{REFERENCES}

[1] E. F. Obert, Elements of Thermodynamics and Heat Transfer. New York: McGraw-Hill, 1949.

[2] L. Beltracchi, "A process engineered safeguard iconic display," in Proc. Symp. New Technology in Nuclear Power Plant Instrumentation and Control, Washington, DC, Nov. 28-30, 1984.

[3] _- "A direct manipulation interface for heat engines based upon the Rankine cycle," IEEE Trans. Syst. Man Cybern., vol. SMC-17, no. 3, pp. 478-487, May/June 1987.

[4] -, "A model-based display," ANS Topical Meeting, Artificial Intelligence and Other Innovative Computer Applications in the Nuclear Industry, Snowbird, UT, Aug. 31-Sept. 2, 1987.

[5] J. Rasmussen and K. J. Vicente, "Cognitive control of human activities and errors: Implications for ecological interface design," presented at the Fourth International Conference on Event Perception and Action, Trieste, Italy, Aug. 24-28, 1987.

[6] K. J. Vicente, "Adapting the DeGroot memory recall paradigm to evaluate interface transparency," Riso National Laboratory, DK-4000 Roskilde, Denmark, Riso-M-2691, Feb. 1988. This work will also appear in Acta Psychologica; special issue on cognitive ergonomics.

[7] R. W. Lindsay and L. W. Schorzman, "Data handling at EBR-II for advanced diagnostic and control work," presented at the EPRI Seminar on Data Acquisition, Control, and Communication in Power Plants, San Diego, CA, Feb. 23-25, 1988.

[8] L. Beltracchi, "Alarm coding of a model-based display," presented at the IEEE Conference on Human Factors and Power Plants, Monterey, CA, June 5-9, 1988.

[9] J. Rasmussen, "Skills, rules, and knowledge; signals, signs, and symbols and other distinctions in human performance models," IEEE Trans. Syst. Man Cybern., vol. SMC-13, no. 3, pp. 257-266, May/ June 1983.

[10] J. Rasmussen and M. Lind, "A model of human decision making in complex systems and its use for design and system control strategies," in Proc. American Control Conference, Arlington, VA, 1982.

[11] A. H. Shapiro, The Dynamics and Thermodynamics of Compressible Fluid Flow. New York: Ronald, 1953. 